Ryznychuk M. A., Pishak V. P. Psychosomatic disorders in people with Shereshevsky-Turner syndrome. Pedagogy and Psychology of Sport. 2018;4(1):22-30. eISSN 2450-6605. DOI http://dx.doi.org/10.5281/zenodo.1186321

http://apcz.umk.pl/czasopisma/index.php/PPS/article/view/16810

Original text

Ryznychuk M. A., Pishak V. P. Psychosomatic disorders in people with Shereshevsky-Turner syndrome. Journal of Education, Health and Sport. 2018;8(1):206-214. eISSN 2391-8306. DOI http://dx.doi.org/10.5281/zenodo.1186321

http://ojs.ukw.edu.pl/index.php/johs/article/view/5320

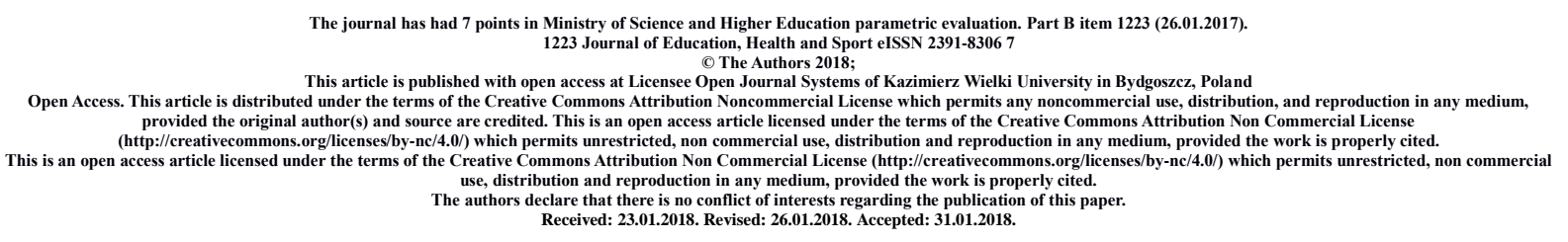

UDC 612.43:618.11-007.12:616.89

\title{
PSYCHOSOMATIC DISORDERS IN PEOPLE WITH SHERESHEVSKY-TURNER SYNDROME
}

\author{
M. A. Ryznychuk, V. P. Pishak*
}

Higher State Educational Institution of Ukraine «Bukovinian State Medical University», Chernivtsi, 2 Teatralna squ. 58001, Ukraine

\author{
* National Academy of Pedagogical Sciences of Ukraine, \\ 52-a Sichovykh Striltsiv str., Kyiv, 04053, Ukraine
}

\section{Abstract}

The article deals with topical issues related to the etiology, peculiarities of the phenotypic manifestations of the Shereshevsky-Turner syndrome in different age groups.

The incidence of Shereshevsky-Turner syndrome among newborn girls is 1: 20001:5000, although some studies mention much more frequent occurrence.

An analysis of the features of mental development in patients with partial or complete monosomy was carried out.

Patients with Shereshevsky-Turner syndrome should be under a constant supervision of clinical psychologists who are aware of the peculiarities of the disease, and it is also necessary to carefully develop social skills and attitudes in social medium, which will be useful in their further social adaptation. 
Key words: Shereshevsky-Turner syndrome, mental development, phenotypic manifestations, girls.

Introduction. Shereshevsky-Turner syndrome (syn.: Bonnevie-Ulrich, Turner syndrome, gonadal dysgenesis, wing-shaped [pterygoid] syndrome, infantilismus pterigionuclearis).

Shereshevsky-Turner syndrome (STs) is adopted in the Russian-language literature reflecting the description by N.A. Shereshevsky (1926) of disorders in the pituitary gland and the adrenal cortex. In the English-language literature Turner syndrome is a more common term [28].

This is the only form of monosomy $(45, \mathrm{X})$ resulting in the birth of an alive infant.

Fetuses with karyotype $45, \mathrm{X}$ occur in $1-2 \%$ of all pregnancies. A high percentage of abortions in this chromosomal pathology should be noted, which indicates the importance of the second $\mathrm{X}$ chromosome for intrauterine survival [16].

The incidence of Shereshevsky-Turner syndrome (STs) among newborn girls is 1: 2000-1:5000, although some studies mention much more frequent occurrence [2].

Etiology. Fetuses 45, X appear, probably, in one of three ways: either from a fetal egg, which, due to a disorder in the correct distribution of chromosomes in meiosis, did not receive a maternal chromosome and was fertilized with a normal sperm cell carrying the $X$ chromosome; or from a normal egg, fertilized by a the sperm cell, which, as a result of pathological meiosis, did not receive either X- or Y-chromosomes; or from a fertilized egg with $\mathrm{XX}$ or $\mathrm{XY}$ in which one of the sex chromosomes is lost from the cell at an early stage of fragmentation when the sex chromosome is lost in a zygote or an early embryo. In this case, the part or even the entire embryo developed from the formed daughter cells 45, X [28].

Along with the true monosomy in all cells $(45, \mathrm{X})$, in $50 \%$ of the patients other forms of chromosomal constitution by sex chromosomes occur. These are the deletions of the short or long shoulder of the X chromosome [46, X, X-; 46XHq-], isochromosome [46, Xi (Xq); 46X, $\mathrm{i}(\mathrm{Xp})]$, ring chromosomes [46, X, r (X)]. The patients who only have a part of the $\mathrm{X}$ cells (XX / X-mosaics, XY / X-mosaics with varying degrees of male gonadal changes), and those that do not only have parts of the $\mathrm{X}$ chromosome (X isochromosome or $\mathrm{X}$ - chromosome), are characterized by a lower level of pathological deviations [9].

And nevertheless, $50-69 \%$ of the total number of patients have a simple complete monosomy $(45, \mathrm{X})$. The only X-chromosome in about $70 \%$ of cases has a father's origin, i.e. the loss of sex chromosomes, usually occurs in fathers (a meiotic nondisjunction) [4, 32]. 
The reason for the rather high loss rate of the $\mathrm{X}$ - or Y-chromosome remains unexplained, as well as why the karyotype $45, \mathrm{X}$, which is so often fatal intrauterine, is compatible with life after delivery.

The lost genes, which are responsible for the Shereshevsky-Turner syndrome phenotype should be located both in the X- and Y-chromosomes [26].

Phenotypic features of patients of different age groups. When infants are born, in $80 \%$ of them lymphatic edema is observed on the back side of the feet, legs, hands and arms, and is preserved for weeks or even months (congenital lymphedema). The legs are small, convex, there is valgus deformation in $45 \%$ of cases [5].

The face: the upper jaw and the palate are narrow (80\%), the lower jaw is relatively small (70\%), the palpebral fissures have internal folds (40\%).

Eye symptoms: synophrys, antimongoloid slant, epicanthus, ptosis (16\%), sometimes lagophthalmos, squinting, hypertelorism, small exophthalmos, blue sclera, cataract, color blindness.

Congenital malformations of the cardiovascular system: pulmonary artery stenosis, interventricular septal defect, non-closed arterial duct, coarctation of aorta. Almost $50 \%$ of patients suffer from the bicuspid aortic valve with complications-the dilation and stratification of the aortic root aneurysm.

Skeletal anomalies: scoliosis, kyphosis, spinal hernia, short middle phalanx of the Vth finger, short III-V metacarpal bones, Madelung's deformity, turkish saddle abnormalities.

Central nervous system: slow thinking, average IQ level - 95\%, hearing impairment [34].

At the older age, the following commonly found symptoms are: small stature, a short webbed neck, disturbed occlusion, deformation and shortening of metatarsal and metacarpal bones, valgus deviation of knee and elbow joints, osteoporosis, anomalies of the genital tract, horseshoe-shaped kidney, telangiectasia of the skin and especially the intestine, brightly pigmented birthmarks on the trunk and neck. In $75 \%$ of the total number of patients there is a low hair growth is on the neck. Cloudy keratoleukoma and decreased sensitivity of the cornea, retrogenie, pupil inward displacement, dilation of the palpebral fissure (Dalrymple syndrome), pallor of the optic nerve discs, narrowing of the arteries, sometimes light sensation is impaired. Less common are microphtalm, colobomae, cataracts and juvenile glaucoma. Low position of the auricles [29]. 
At puberty age, there is a delayed growth, a short neck, no signs of puberty, no feminization, the secondary sex characteristics are undeveloped, although the level of gonadotrophins rises by that time [33].

Patients with monosomy $(45, \mathrm{X})$ are usually frigid, sterile, they have no sexual desire. In this period there is primary amenorrhea. The underdevelopment of the mammary glands, as well as a number of other symptoms, is due to insufficient levels of estrogens and an excess of pituitary gonadotropins.

Adults have such skeletal disorders: shortening of IV and V metacarpal bones, dysmorphia, a short neck, a high palate, changes in nails in the feet and hands, flattened chest, low hair growth around the neck. The incidence of these dysmorphic lesions is $70 \%$ of the total number of patients. Large and small lips of pudendum are with hypoplasia, gonads are not defined, the vagina is narrow, the uterus is small [8].

Typical anomalies in the Shereshevsky-Turner syndrome can be grouped in three directions: 1) primary hypogonadism; 2) small stature (characteristic for $100 \%$ of patients); 3) congenital malformations (incidence of anomalies from 60 to $85 \%$ of patients).

On the part of the genital organs and secondary genital signs, there is a lack of gonads (agenesis), dysgenesia of the ovaries (90\%), hypoplasia of the uterus and uterine tubes, primary amenorrhea, poor hair hair distribution on the pubis and in the armpits, underdevelopment of the mammary glands, illusion of a large distance between the nipples, as the result of a wide, shield-like chest (80\%). Due to the gonadal dysgenesis, the development of the ovaries is impaired; they are represented by narrow connective tissues located in the true pelvis [18].

Due to the absence of the ovary, the Wolffian ducts undergo atresia, and the Mbllerian ones give rise to the uterus and upper vagina. Occasionally, there are elements of the testicle in one of the dysgenic gonads, but the production of androgens is small and does not interfere with the development of the internal and external genitalia by the female type, though it can cause the clitoris hypertrophy.

Women with Shereshevsky-Turner syndrome more frequently have osteoporotic bone fractures, autoimmune thyroiditis, colitis, types 1 and 2 diabetes mellitus. The cause of diabetes mellitus and disorders of the thyroid gland is unknown. Obviously, the estrogen deficiency causes an increased incidence of atherosclerosis and strokes.

The clinical picture changes significantly when a hormone-active tumor (gonocytoma) is formed from the cellular elements of the rudimentary gonad. If the tumor produces 
estrogens, feminization increases, and if androgens - virilization (increased clitoris, hirsutism) develops.

Features of mental development. Since the mental retardation is not typical of Shereshevsky-Turner syndrome, the problem of somatogenic and mental disorders, as well as of psychosomatic relationships deserves special attention [27].

According to Haverkamp et al. [6] when considering the relationship between somatic disease (in our case, a hereditary illness (STs)) and a mental disorder, it is advisable to distinguish between the following five types of the relationship: 1) psychological factors as the cause of a somatic illness; 2) mental disorders manifested by somatic symptoms; 3) the psychological consequences of a somatic illness: a) organic disorders; b) dysfunctions; 4) mental disorder and somatic illness, accidentally coinciding in time; 5) somatic complications of mental disorders.

Concerning Shereshevsky-Turner syndrome, it acts as a psycho-traumatic event and belongs to the category of reactive conditions - the psychological consequences of a hereditary disease.

Girls with STs usually have normal intelligence, except the patients with mosaic karyotype, and ring $X$ chromosome. Migeon et al. [12] demonstrated a the relationship between the absence of an $\mathrm{X}$ chromosome or the presence of an ring $\mathrm{X}$-chromosome in women with STs and severe intellectual impairment. Zenger-Hain et al. [35] showed that women with a similar karyotype, but whose $\mathrm{r}$ (X) chromosome was inactivated, had a normal intelligence. These results have also been demonstrated by other researchers [7].

A significant number of women with STs have a deficit in certain areas of intellectual activity. They usually have normal verbal abilities, but nonverbal skills such as visual-spatial processing [13, 19], motor coordination [21, 23] and perceptual abilities [1] are impaired. This may result in difficulties with mathematics, and especially with solving constructive tasks, a poor sense of direction and difficulties with driving instructions. They can also have a deterioration of short-term memory and attention [10, 13]. In addition, the executive function (the ability to plan and perform multistage tasks) of some women with STs [20, 21] may be impaired.

It has been shown that the severity of cognitive impairment is associated with a karyotype. Murphy et al. [14] demonstrated differences in brain metabolism between women with STs and the control that correspond to specific cognitive impairments [15]. Anatomical differences in the development of the brain in women with STs, regardless of their karyotype, have also been demonstrated. Murphy et al. [14] demonstrated smaller dimensions of the 
hippocampus and of the right parietal lobe in women with STs, Reiss et al. [20] showed a decrease in the volume of parietal and occipital lobe in girls with STs. Ross et al. [25] studied the effect of estrogen therapy on motor function and non-verbal abilities in girls with STs. They found that patients who received estrogen replacement therapy performed non-verbal and visual-motor tasks much faster than the untreated ones. Ross et al. [22] also studied the effect of somatotropic therapy on cognitive function in girls with STs but failed to find a significant difference after the therapy. It is likely that some deficit of cognitive development is directly related to the anomaly of the $\mathrm{X}$ chromosome, as evidenced by the differences in the verbal and visual-motor function between patients with $45, \mathrm{X}$ monosomy and mosaic variants of STs [13]. And the cognitive deficits, such as memory and reaction time, results from the estrogen deficiency and is, therefore, potentially reversible.

Girls with STs had significantly more problems in social relationships and school performance, and they were more likely to have symptoms of hyperactivity and attention deficit syndrome than the control subjects. According to their parents, girls with STs were less socially competent (for example, they had fewer friends, spent less time with friends) than those in the control group [11].

Skus et al. [30] showed that girls $45, \mathrm{X}$ with STs with father's X chromosome, had bettert verbal and executive skills than the individuals whose chromosome $\mathrm{X}$ was maternal. Despite these problems, a significant number of women with STs have higher education, but most of them find it difficult to find a job. Sybert [31] analyzed that 33\% of adults with STs entered the university compared to $19 \%$ of other American women, and $10 \%$ were students at postgraduate courses. Similar findings were obtained in Japan [17]. A significant number of women with STs work as nannies with children or in hospitals, as secretaries, sellers or in public catering.

Girls with STs have specific character traits. It is harder for them to make friends and to be engaged in sexual relationships. This may be due, in particular, to difficulties in understanding the non-verbal communication, but may also be due to low self-esteem as a result of small stature and late puberty. Delooz et al. [3] analyzed the low self-esteem of 50\% of women, as well as adolescent girls with STs [23]. Self-esteem and psychological wellbeing in adulthood can be strengthened in the women, who started substitution therapy with estrogens at the age under 14 years [24].

Conclusion. Patients with Shereshevsky-Turner syndrome should be under a constant supervision of clinical psychologists who are aware of the peculiarities of the disease, and it is 
also necessary to carefully develop social skills and attitudes in social medium, which will be useful in their further social adaptation.

\section{References}

1. Bender B, Puck M, Salbenblatt J, Robinson A. Cognitive development of unselected girls with complete and partial X monosomy. Pediatrics, 1984; 73: 175-182.

2. Burnett AC, Reutens DC, Wood AG. Social cognition in Turner's Syndrome. J Clin Neurosci. 2010; Mar; 17(3): 283-286. doi: 10.1016/j.jocn.2009.09.006.

3. Delooz J, Van-den-Berghe H, Swillen A, Kleczkowska A, Fryns JP. Turner syndrome patients as adults: a study of their cognitive profile, psychosocial functioning and psychopathological findings. Genet Couns., 1993; 4: 169-179.

4. Elgar K, Campbell R, Skuse DH. Are you looking at me? Accuracy in processing line-of-sight in Turner syndrome. Proc. R. Soc. Lond. B. Biol. Sci., 2002; 269: 2415-2422. DOI: $10.1098 /$ rspb.2002.2173

5. Emery NJ. The eyes have it: the neuroethology, function and evolution of social gaze. Neurosci Biobehav Rev., 2000; 24: 581-604.

6. Haverkamp F, Keuker T, Kaiser G, Noeker M, Zerres K, Reitz C. Social cognition in relation to visuospatial cognitive styles in Ullrich-Turner syndrome: evidence for a selective deficit in social context dependent visual integration. In: Saenger P, Pasquino AM, eds. Optimizing health care for Turner patients in the 21st century. Amsterdam: Elsevier Science, 2000; 97-103.

7. Jani MM, Torchia BS, Pai GS, Migeon BR. Molecular characterization of tiny ring $\mathrm{X}$ chromosomes from females with functional $\mathrm{X}$ chromosome disomy and lack of cis $\mathrm{X}$ inactivation.Genomics, 1995; 27: 182-188. DOI:10.1006/geno.1995.1022

8. Lesniak-Karpiak K, Mazzocco MM, Ross JL. Behavioral assessment of social anxiety in females with Turner or fragile X syndrome. J Autism Dev Disord., 2003; 33: 5567.

9. Lynn PM, Davies W. The 39, XO mouse as a model for the neurobiology of Turner syndrome and sex-biased neuropsychiatric disorders. Behav. Brain. Res. 2007; 179: 173-182. doi:10.1016/j.bbr.2007.02.013

10. McCauley E, Kay T, Ito J, Treder R. The Turner syndrome: cognitive deficits, affective discrimination, and behavior problems. Child Dev., 1987; 58: 464-473.

11. McCauley E., Feuillan P., Kushner H., Ross J.L. Psychosocial development in adolescents with Turner syndrome. J. Dev. Behav. Pediatr., 2001; 22(6): 360-365. 
12. Migeon BR, Luo S, Jani M, Jeppesen P. The severe phenotype of females with tiny ring $\mathrm{X}$ chromosomes is associated with inability of these chromosomes to undergo $\mathrm{X}$ inactivation. Am. J. Hum. Genet., 1994; 55: 497-504.

13. Murphy DG, Allen G, Haxby JV, Largay KA, Daly E, White BJ, Powell CM, Schapiro MB. The effects of sex steroids, and the X chromosome, on female brain function: a study of the neuropsychology of adult Turner syndrome. Neuropsychologia, 1994; 32: 13091323.

14. Murphy DG, DeCarli C, Daly E, Haxby JV, Allen G, White BJ, McIntosh AR, Powell CM, Horwitz B, Rapoport SI. X-chromosome effects on female brain: a magnetic resonance imaging study of Turner's syndrome. Lancet, 1993; 342: 1197-1200.

15. Murphy DG, Mentis MJ, Pietrini P, Grady C, Daly E, Haxby JV, De-La-Granja M, Allen G, Largay K, White BJ, Powell CM, Horwitz B, Rapoport SI, Schapiro MB. A PET study of Turner's syndrome: effects of sex steroids and the $\mathrm{X}$ chromosome on brain. Biol Psychiatry, 1997; 41: 285-298.

16. O’Connor J, Fitzgerald M, Hoey H. The relationship between karyotype and cognitive functioning in Turner syndrome. Ir. J. Psychol. Med., 2000; 17: 82-85. doi.1017/S0790966700005826.

17. Okada Y. The quality of life of Turner women in comparison with grown-up GH-deficient women. Endocr. J., 1994; 41: 345-354.

18. Pavlidis K, McCauley E, Sybert VP. Psychosocial and sexual functioning in women with Turner syndrome. Clin Genet., 1995; 47: 85-89.

19. Pennington BF, Heaton RK, Karzmark P, Pendleton MG, Lehman R, Shucard DW. The neuropsychological phenotype in Turner syndrome. Cortex, 1985; 21: 391-404.

20. Reiss AL, Mazzocco MM, Greenlaw R, Freund LS, Ross JL. Neurodevelopmental effects of X monosomy: a volumetric imaging study. Ann. Neurol., 1995; 38: 731-738. doi: 10.1002/ana.410380507.

21. Romans SM, Stefanatos G, Roeltgen DP, Kushner H, Ross JL. Transition to young adulthood in Ullrich-Turner syndrome: neurodevelopmental changes. Am. J. Med. Genet., 1998; 79(2): 140-147.

22. Ross JL, Feuillan P, Kushner H, Roeltgen D, Cutler Jr GB. Absence of growth hormone effects on cognitive function in girls with Turner syndrome. J. Clin. Endocrinol. Metab., 1997; 82(6): 1814-1817. doi: 10.1210/jcem.82.6.4003.

23. Ross JL, Kushner H, Roeltgen DP. Developmental changes in motor function in girls with Turner syndrome. Pediatr. Neurol., 1996; 15(4): 317-332. 
24. Ross JL, McCauley E, Roeltgen D, Long L, Kushner H, Feuillan P, Cutler Jr GB. Self-concept and behavior in adolescent girls with Turner syndrome: potential estrogen effects. J. Clin. Endocrinol. Metab., 1996; 81(3): 926-931. doi 10.1210/jcem.81.3.8772552.

25. Ross JL, Roeltgen D, Feuillan P, Kushner H, Cutler Jr GB. Effects of estrogen on nonverbal processing speed and motor function in girls with Turner's syndrome. J. Clin. Endocrinol. Metab., 1998; 83(9): 3198-3204. doi: 10.1210/jcem.83.9.5087.

26. Ross JL, Roeltgen D, Zinn, AR. Cognition and the sex chromosomes: studies in Turner syndrome. Horm. Res., 2006; 65(1): 47-56. doi: 10.1159/000090698.

27. Ross JL, Zinn AR, McCauley E. Neurodevelopmental and psychosocial aspects of Turner syndrome. Ment. Retard. Dev. Disabil. Res. Rev. 2000; 6(2): 135-141.

28. Saenger P. Turner's syndrome. N. Engl. J.Med., 1996; 335: 1749-1754.

29. Siegel PT, Clopper R, Stabler B. The psychological consequences of Turner syndrome and review of the National Cooperative Growth Study psychological substudy. Pediatrics, 1998; 102(2 Pt 3): 488-491.

30. Skuse DH, James RS, Bishop DV, Coppin B, Dalton P, Aamodt-Leeper G, Bacarese-Hamilton M, Creswell C, McGurk R, Jacobs PA. Evidence from Turner's syndrome of an imprinted Xlinked locus affecting cognitive function. Nature, 1997; 387(6634): 705708. DOI:10.1038/42706.

31. Sybert VP. The adult patient with Turner syndrome. In: Albertsson-Wikland K, Ranke MB, eds. Turner syndrome in a life span perspective: research and clinical aspects. Amsterdam: Elsevier, 1995; 205-218.

32. Temple CM, Carney RA. Intellectual functioning of children with Turner syndrome: a comparison of behavioural phenotypes. Dev. Med. Child. Neurol., 1993; 35(8): 691-698.

33. Toublanc JE, Thibaud F, Lecointre C. Psychosocial and sexual outcome in women with Turner syndrome. Contracept. Fertil. Sex., 1997; 25(7-8): 633-638.

34. Van Dyke DL, Wiktor A, Roberson JR, Weiss L. Mental retardation in Turner syndrome. J. Pediatr., 1991; 118(3): 415-417.

35. Zenger-Hain JL, Wiktor A, Goldman J, Van-Dyke DL, Weiss L. X-inactivation pattern in an Ullrich-Turner syndrome patient with a small ring $\mathrm{X}$ and normal intelligence. Am. J. Med. Genet., 1993; 47(4): 490-493. doi: 10.1002/ajmg.1320470412. 